\title{
De la correspondencia semántica y gramatical entre los sies: apuntes para un estado de la cuestión
}

\author{
Claudio Garrido Sepúlveda* \\ Universidad Católica del Maule, Chile
}

\begin{abstract}
Resumen
En el siguiente trabajo, exploramos la tesis de Andrés Bello (1847) sobre una aparente identidad entre las partículas si y sí. Para ello, nos referimos al origen histórico de estas partículas y describimos los valores que han codificado tanto en el castellano medieval como en el moderno. Además, presentamos un panorama de la tradición de autores que, directa o indirectamente, se han acercado a la propuesta de Bello, ya sea en el español o en otras lenguas. De este modo, el análisis sistemático de los datos nos conduce a valorar y a matizar la idea de una correspondencia entre todos los síes.
\end{abstract}

Palabras clave: Andrés Bello, Si condicional, Si interrogativo, Si adverbial.

Para correspondencia, dirigirse a: Claudio Garrido Sepúlveda (cgarrido@ucm.cl), Avenida San Miguel 3605, Talca, Facultad de Ciencias de la Educación, Departamento de Lengua Castellana y Literatura. 


\title{
ABOUT SEMANTIC AND GRAMMATICAL CORRESPONDENCE BETWEEN SIES: NOTES FOR A STATE OF THE ART
}

\begin{abstract}
In the following work, we explore the thesis of Andrés Bello (1847) on an apparent identity between the particles $s i$ and si. Thus, we describe the historical origin of these particles and the values that they have codified both in medieval and modern Spanish. Moreover, we present an overview of the tradition of authors who, directly or indirectly, have approached to Bello's proposal, either in Spanish or in other languages. Therefore, the systematic analysis of data leads us to qualify the idea of a correspondence between all sies.
\end{abstract}

Keywords: Andrés Bello, Conditional Si, Interrogative Si, Adverbial Sí.

Recibido: 17/10/18 Aceptado: 16/01/19

\section{INTRODUCCIÓN}

El tratamiento gramatical que tradicionalmente han recibido el denominado si condicional y el sí afirmativo manifiesta, a grandes rasgos, una distinción categorial: el primero es descrito como una conjunción subordinante, en tanto que el segundo es presentado como un adverbio de polaridad positiva. No obstante, más allá de la mera homofonía que superficialmente los equipara, desde una tradición paralela y menos visible, se han aducido razones agudas a la par que controversiales que sugieren la existencia de una correspondencia más sustancial o primitiva entre ambas partículas, ya sea por su cercanía nocional como por su aparente afinidad categorial. Dicha tradición se remonta a la propuesta de Andrés Bello (1847: § 410 y ss.), quien abogaba por una identidad entre todos los síes.

El disenso que introduce este postulado suscita más de un interrogante: ¿cuáles son y cuáles han sido las funciones de los síes? ¿Qué gramáticos han suscrito, sea parcial o totalmente, la propuesta de Bello? ¿Qué argumentos han sido referidos y, sobre su base, qué conclusiones se podrían formular? Enunciar, al menos en parte, la respuesta a tales preguntas constituye el objetivo global de nuestro estudio. El siguiente trabajo, por tanto, se perfila como un ejercicio de reflexión gramatical y de análisis bibliográfico 
cuyo producto esperamos que se conciba como un status quaestionis que sirva de referencia orientativa para futuras indagaciones en el tema. En concreto, cinco son las exploraciones que procuramos emprender: primero, presentamos una revisión sintética de la procedencia de los síes (vid. § 2); segundo, describimos una gama representativa de los valores de tales partículas en el español moderno (vid. § 3); tercero, sobre la base de la descripción anterior, establecemos un cotejo con los valores de los síes en el castellano antiguo (vid. § 4); cuarto, hacemos un somero recorrido conceptual por la tradición de autores que podrían situarse bajo el alero de Andrés Bello (vid. § 5), quinto, sistematizamos los argumentos clave que favorecen dicha tesis (vid. § 6) y, a la postre, reflexionamos sobre cómo el conjunto integral de los datos - la sincronía, la diacronía y el recorrido bibliográfico- conduce a fortalecer o a matizar la tesis de la correspondencia entre todos los sies (vid. §7).

Es preciso destacar que nuestra indagación concede especial importancia a la diacronía, sobre todo al estado de lengua del castellano medieval, en tanto modelo contrastivo respecto del español actual. Tal elección se justifica en el hecho de que entre ambos estadios son más nítidas las discontinuidades históricas que parecen acentuar la tesis de la correspondencia de síes. Además, el castellano medieval es un punto de partida más aventajado para asomarse a la gama de valores de los étimos latinos que anteceden a las partículas en cuestión y, en adición, dicho estado de lengua -como argumentaremos- constituye un eslabón fundamental cuando se trata de engarzar las funciones de los sies.

\section{PROCEDENCIA}

El si condicional del español moderno -así como las partículas análogas del resto de las lenguas románicas $-{ }^{1}$ proviene de la conjunción latina $\mathrm{SI}^{2}$. Esta, a su vez, se origina en el locativo de *sos $\left({ }^{*}\right.$ sei $)$, un hipotético pronombre

\footnotetext{
$S e$, en portugués, occitano e italiano; y si, en catalán y francés. La única lengua romance que no expresa la condicionalidad mediante un derivado del Sİ latino es el rumano (dacă). Para una descripción más acabada de los usos de $s i$ en toda la Romania, véase Vasco de Gama (1979).

2 Como tesis alternativa, Nicholson (1938) ha sostenido la débil idea de que el $s i$ condicional proviene del latín clásico SIT.
} 
demostrativo del indoeuropeo (Monteil 1973: 233). El adverbio afirmativo $s i ́$, en cambio, procede del adverbio deíctico de modo SīC, desde el cual proviene, asimismo, el adverbio de manera $a s i^{3}$. Este SİC, no obstante, tiene su origen en la forma $\mathrm{SI} \mathrm{CE}^{4}$ que, al igual que lo ocurrido con Sİ, constituye una forma locativa de una raíz pronominal *sa emparentada con *sos (Lewis y Short 1879). Por lo mismo, es evidente que la partícula si y el adverbio de afirmación sí están etimológicamente emparentados (Ernout y Meillet 1959). Sin embargo, en el latín, las partículas SĪ y SİC ya estaban diferenciadas, de ahí que los diccionarios latinos cataloguen la primera como una conjunción y la segunda como un adverbio. Además, en el caso de la conjunción, se distinguían las dos funciones sintácticas básicas que también hereda el español: complementante de subordinadas interrogativas y rector de cláusulas condicionales (Ernout y Thomas 1989: § 321).

En el caso del castellano, como ya indicamos, el tratamiento gramatical y lexicográfico que establece una distinción categorial entre las partículas $s i$, sí y así es el que ha primado: si es procesada como una conjunción subordinante, sí como un adverbio afirmativo y así como un adverbio de modo ${ }^{5}$. Tales funciones básicas pueden retratarse como sigue.

(1a) Si de verdad quisieras ir, lo intentarías.

(1b) A. ¿Viste esa película?

B. $S i$ la vi.

(1c) Es peligroso que corras así.

No obstante, como veremos, este es tan solo un boceto simplificado de los valores de tales partículas. A continuación, pues, nos referiremos a la amplia gama de funciones de si y sí.

3 El adverbio latino SĪC tiene herederos en todas las lenguas romance: en portugués, assim; en catalán, així; en occitano, aissi; en francés, aisí; en italiano, cosí; en sardo, gasi; en rumano, așa. No obstante, los modernos adverbios afirmativos de cada lengua no siempre son herederos de SĪC. Por ejemplo, en occitano, se adoptó òc; en francés, oui, y en rumano, $d a$.

4 Esta forma SĪCE ha sido explicada como un compuesto de si más el elemento de refuerzo -c(e) (Montolío 1990: 120).

5 Dicha distinción se plantea con nitidez en el Nuevo tesoro lexicográfico de la lengua española (NTLLE), desde la gramática de Nebrija (1495) en adelante. 


\section{VALORES DE LOS SÍES EN EL ESPAÑOL MODERNO}

\subsection{LA CONJUNCIÓN SI}

En términos sintácticos, la partícula si es un potencial elemento constitutivo de tres diferentes estructuras oracionales: puede actuar como la partícula subordinante de una cláusula adyacente a otra principal, es decir, las llamadas subordinadas adverbiales impropias -o bipolares-, contexto en que adquiere típicamente su valor condicional (2a); también puede fungir como partícula subordinante de una oración completiva de carácter interrogativo indirecto (2b), y como elemento especificador de una oración simple - no incrustada-, cuya función es la de un marcador de modalidad (Hernanz 2012: 153) (2c) ${ }^{6}$.

(2a) Si estudias todos los días, mejorará tu rendimiento.

(2b) Aún no sabemos si el responsable fue él.

(2c) iSi pudieras ayudarme por esta vez!

Tales valores, no obstante, bien podrían reagruparse en dos funciones primordiales y diferenciadas: como elemento rector, subordinante o complementante $(2 \mathrm{a}-\mathrm{b})$ y como marcador de modalidad en oraciones radicales (2c).

Sin duda, los principales estudios que abordan la partícula si son aquellos que la sitúan en el contexto de una estructura condicional. A propósito de estas oraciones, en Garrido Sepúlveda (2015, 2017), hemos abogado, siguiendo a Veiga $(1991,1999)$, por una tipología binaria basada en las oposiciones modales que pueden reconocerse en igualdad de circunstancias temporales en el seno de la prótasis condicional introducida por $s i$. En virtud de este criterio, solo es operativa la oposición del valor de no irrealidad (3a y c) frente al de irrealidad ( 3 b y d).

(3a) Si vas mañana, lo sabrás.

(3b) Si fueras mañana, lo sabrías.

(3c) Si fuiste ayer, lo supiste.

(3d) Si hubieras ido ayer, lo habría sabido.

6 Eventualmente, todas las funciones de la partícula si podrían ser clasificadas en alguna de estas estructuras. Felisa Sanjuán (1999), por ejemplo, procesa una gran cantidad de matices semánticos de si y los organiza con el mismo esquema. 
Para los efectos de este artículo, es de notar que la no irrealidad exhibe un grado de incertidumbre respecto a la proposición que encabeza la partícula $s i$, de ahí que en este modelo tipológico no sean tratadas como oraciones condicionales reales. Dicho de otro modo, en (3a y c) el acto de ir mañana o de haber ido ayer no ocurre necesariamente de facto. Por otra parte, cabe señalar que la irrealidad conlleva, sobre todo en orientación de pasado, una negación implícita. Así, pues, (3b) presupone los enunciados No fuiste y No supiste.

Respecto del si completivo, Alarcos (1994: 238) puntualiza que esta partícula transpone una oración interrogativa a una función sustantiva, de modo que el objeto directo del ejemplo (2b) se correspondería con la interrogativa polar ¿Fue él el responsable o no? Si bien la interpretación más común es la de atribuir un término de polaridad negativa implícito (Aún no sabemos si el responsable fue él o no), también es posible que el si completivo introduzca interrogativas indirectas de alternativa (Aún no sabemos si el responsable fue él o si fue su hermana) ${ }^{7}$.

Hernanz (2012) propone la existencia de un contenido modal asociado a la partícula si que valida solo construcciones no asertivas, de ahí la agramaticalidad del enunciado *Me aseguró si el responsable fue él. Por el contrario, el subordinante que sí que admite construcciones asertivas del tipo Me aseguró que el responsable fue él. Por lo tanto, la partícula si parece ser necesaria para trazar una suerte de correspondencia con verbos de modalidad hipotética. Dicho de otro modo, además de operar como subordinante, si pone en suspensión la polaridad, de manera que se inserta un valor de incertidumbre -ni afirmativo ni negativo- en cuanto al contenido polar de la proposición que introduce. Por cierto, este matiz hipotético o de polaridad suspendida es similar al que emerge en las oraciones condicionales no irreales.

En relación con el rol de si como partícula modal en oraciones simples, Sanjuán (1999: 43) explica que "en muchos casos permanece el sentido condicional, pero, en otros, la conjunción es casi expletiva". En efecto, en oraciones desiderativas como (4a y c), pareciera haber una apódosis elíptica, tal como se actualiza entre corchetes. Respecto de estas condicionales escindidas o truncadas, Hernanz (2012) ha sugerido la existencia de una restricción modal de tipo irreal, hecho que se refleja en las formas verbales seleccionadas: pluscuamperfecto (4a) e imperfecto de subjuntivo (4c). Esto 
también explicaría la agramaticalidad de condicionales no irreales escindidas (4b y d).

(4a) ¡Si tan solo le hubiéramos hecho caso, [no estaríamos lamentándonos ahora]!

(4b) $*_{i}$ Si tan solo le habíamos hecho caso!

(4c) ¡Si supieras cómo te aprecia, [no serías tan descortés con él]!

(4d) $*_{i} S i$ supiste cómo te aprecia!

En este tipo de construcciones es frecuente añadir el refuerzo tan solo (4a). En este sentido, hay una semejanza con las oraciones desiderativas del inglés if only. El efecto expresivo conseguido en estas oraciones es el mismo que se logra a través de partículas interjectivas como ojalá con valor desiderativo: ¡Ojalá le hubiéramos hecho caso!, ¡Ojalá supieras cómo te aprecia!

Asimismo, hay oraciones propiamente radicales en que no es posible actualizar una hipotética apódosis. Para Alarcos (1994: 383), en tales casos la partícula $s i$ en realidad funciona como un adverbio que intensifica el contenido comunicativo. Estas construcciones, además, ostentan matices semánticos de 'protesta' o 'reclamación' (5a-b).

(5a) ¡Si ya guardé los juguetes!

(5b) iSi le di las gracias!

En estos casos, es palmaria la afinidad con el sí afirmativo, pues el énfasis comunicativo de este $s i$ es justamente el de reforzar la polaridad positiva de la oración, tal como sería expresado con el adverbio en los segmentos Sí, ya guardé los juguetes; Sí, le di las gracias.

La partícula $s i$, además, ha podido encabezar oraciones interrogativas totales como las presentadas en $(6 a \text { y } 7 a)^{8}$. Estas estructuras tenían gran funcionalidad en el castellano antiguo ${ }^{9}$, pero ya casi no tienen vigencia. En la actualidad, su uso parece transmitir un valor retórico o enfático similar a aquel que se expresa mediante el adverbio acaso. Según Hernanz (2012) estas construcciones, además, tienen una restricción temporal, por la cual solo aceptan formas verbales de futuro, de ahí la agramaticalidad de (6b y $7 b$ ).

\footnotetext{
8 Tales usos divergen de estructuras interrogativas del tipo ¿Y si después te arrepientes...?, pues aquí es obligatoria la presencia de la conjunción $y$, además que hay una apódosis sobrentendida del tipo ¿̇...qué pasará?

9 Un ejemplo clásico figura en el Cantar de mio Cid: “¿Commo son las saludes de Alfons

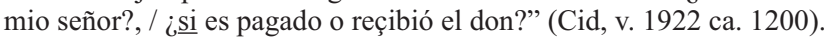


(6a) ¿Si será verdad lo que dice?

(6b) *iSi es verdad lo que dice?

(6c) No sé si será verdad lo que dice.

(7a) ¿Si habré yo visto visiones?

(7b) * ¿Si vi yo visiones?

(7c) No sé si yo habré visto visiones.

[(6a) Apud RAE 2009: § 42.7c; (7a) Apud Alarcos 1994: §452]

En apariencia, habría una correspondencia semántica entre las interrogativas indirectas $(6 \mathrm{c}$ y $7 \mathrm{c})$ y las interrogativas independientes encabezadas por $s i$ (6a y 7a), pero lo cierto es que en el español moderno tal correspondencia está interrumpida, debido a que las segundas solo son gramaticales con valor retórico.

Como último aspecto de esta descripción, cabe señalar que la partícula si suele combinarse con otras partículas que intensifican su significado y/o le imprimen nuevos valores semánticos. Consideremos los siguientes enunciados.

(8a) A. ¿Ya saliste de vacaciones?

B. ¿Qué?

A. Que si ya saliste de vacaciones.

(8b) Está prohibida la entrada, excepto si eres socio.

(8c) Si bien lo llevamos a un parque, no quiso jugar.

(8d) Come como si tuviera mucha hambre.

(8e) Por si te interesa, Martín está vendiendo sus libros.

Así, pues, en (8a), el conjunto que si suscita un valor ecoico, posible en el contexto dialógico; en (8b), excepto convierte la prótasis en una conditio sine qua non; en (8c), si bien exhibe un valor concesivo; en (8d), la fórmula como si inserta una comparación de carácter hipotético; y en (8e), la estructura es de tipo causativo-condicional. En algunos de estos enunciados, las combinaciones presentan cierto nivel de fijación y su significado no es meramente composicional. Por lo mismo, hay procesos de gramaticalización operando, tal como el que afecta a la fosilizada locución por si acaso.

\subsection{El ADVERBIO $S I$}

La gramática tradicional ha codificado sí como un adverbio afirmativo -en oposición al adverbio negativo no- $\mathrm{y}$, como tal, constituiría un adjunto verbal 
o complemento circunstancial. En la perspectiva de la gramática teórica, no obstante, sí y no son procesadas como manifestaciones de un núcleo funcional denominado sintagma de polaridad (Laka 1990, Hernanz 2006, González Rodríguez 2007). Es interesante, notar, junto con Rodríguez Molina (2014: 863) ${ }^{10}$ que "en español se produce una asimetría en la expresión gramatical de las partículas de polaridad, ya que la polaridad positiva [ $\mathrm{Pol}$, $+P o s]$ carece de marcas morfológicas que la hagan explícita [...], mientras que la negativa $[\mathrm{Pol},+\mathrm{Neg}]$ debe marcarse siempre". De ahí que el enunciado (9a) tenga polaridad positiva, aun cuando carezca de marcas formales. Por el contrario, en segmentos de polaridad negativa como (9b), la inclusión de una marca formal es obligatoria.

(9a) Ø le contó el secreto.

(9b) No le contó el secreto.

(9c) Sí le contó el secreto.

La diferencia entre (9a) y (9c) reside en que, en este último enunciado, sí tan solo le confiere énfasis a la polaridad positiva. En efecto, tal es su valor primordial.

En términos más específicos, sí posee dos funciones (RAE 2009: § 40.7). Primero, es una proforma oracional o anafórico que actualiza el contenido de un enunciado previo (10a-b). Como tal, puede conformar un enunciado per se (10a), aunque también admite la compañía del enunciado que actualiza (10b).

(10a) A. ¿Ya viste los resultados del examen? B. Sí.

(10b) A. ¿Ya viste los resultados del examen? B. Si, ya los vi.

Segundo, sí es el modificador de un sintagma verbal (11a-b). En este sentido, puede articular un valor focal, típicamente contrastivo (11a), o bien, puede figurar como refuerzo afirmativo (11b). En ambos contextos es posible combinar el adverbio sí con la conjunción que.

(11a) A. No respondiste mi correo.

B. Si (que) te respondí.

10 Dado que Rodríguez Molina (2014) analiza in extenso las propiedades gramaticales de si y sus cambios históricos, nos valemos de sus distinciones como hipótesis de partida respecto de la configuración de sí en español antiguo. 
(11b) A. Recuerda saludar a tu prima.

B. Sí lo haré.

A esta descripción, cabe añadir que ambas funciones - la de proforma oracional y la de modificador de SV-pueden reproducirse simultáneamente, tal como se ejemplifica en (12).

(12) A. Mañana cambian la hora.

B. Sí, sí lo sé.

\section{VALORES DE LOS SÍES EN EL CASTELLANO MEDIEVAL ${ }^{11}$}

\subsection{EL SI CONDICIONAL}

Tras el análisis de los usos modernos de la partícula $s i$, se observan tres funciones fundamentales: un $s i$ condicional, un si completivo y un $s i$ especificador. Ahora bien, el cotejo con los datos del castellano medieval sugiere, a grandes rasgos, que tales valores ya operaban en el español antiguo, pero con algunas diferencias importantes de precisar.

En relación con el primer valor, hay indicios que sugieren que los hablantes podrían haber percibido el significado del si condicional en términos de una proforma catafórica similar, en significado, al conector de este modo ${ }^{12}$. Esto se evidencia en casos en que los traductores del siglo XIII y XV se valían del adverbio asi para traducir partículas del latín (13ac) y del hebreo (14a-c) equivalentes a $s i-s i$ e $i m$ respectivamente-, lo cual sugiere que en su gramática interna había una estrecha relación entre si y $a s i ́$, y que podría haber un origen o pasado proadverbial de $s i$, favorecido por su parentesco etimológico con el sic latino.

11 En esta sección nos valemos del análisis que emprendimos en nuestra investigación doctoral sobre oraciones condicionales y estructuras afines (Garrido Sepúlveda 2017: 374 y ss.). Los datos procesados fueron extraídos del corpus Biblia Medieval (Enrique-Arias 2008), base de datos representativa de los siglos XIII y XV.

12 La misma idea, por cierto, se ha sostenido respecto de la alternancia entre las partículas latinas si y sic. Considérese el conocido ejemplo citado por Ernout y Thomas (1989) de Captivi de Plauto: "Meam rem non cures, si recte facias", cuyo equivalente en español sería No deberías ocuparte de mis asuntos, así harías bien. 
(13a) "Quod si putatis inmundam esse terram possessionis vestrae, transite ad terram in qua tabernaculum Domini est [...]" (Josué 22:19, Vulgata)

(13b) “Assí cuidades que sea suzia la tierra del vuestro eredamiento, passat a la tierra do es la tienda del Señor Dios [...]" (Josué 22:19, Prealfonsina, s. XIII)

(14a) “'im-yāmušûhahuqqîmhā’ēllehmilləfānaynə’um-yəhwâgamzera' yiśə rā’ēlyišəbətûmihəywōtgōōyləfānaykāl-hayyāmîm:” (Jeremías 31:36, Biblia Hebrea Transliterada)

(14b) “Así se pueden tirar estas costumbres de delante mí - dize el Señor-, tan poco el linaje de Israel se puede estorbar de ser gente delante mí en todos los días" (Jeremías 31:36, E5/E7, s. XV)

Otro dato que apunta en una dirección similar reside en el hecho de que ambas partículas podían funcionar como los términos de oraciones de carácter hipotético (15a-b). En tal contexto, si actúa como una proforma con el valor semántico de 'del modo en que'.

(15a) “Si puede seer quebrantado el mío paramiento con el día e con la noch, que non sean días ni noches en so tiempo, assí será quebrantada la mi postura con David, mío siervo [...]" (Jeremías 33:20-21, Prealfonsina, s. XIII)

(15b) "Si se baldara la mi pleitesía de día e la mi pleitesía de noche, para non ser día nin noche en su sazón, así la mi pleitesía será baldada de David, mi siervo [...]" (Jeremías 33:20-21, Santillana, s. XV)

Tal observación coincide con la propuesta de Polo (1971: 58-60), autor que ha aludido al aparente origen comparativo de si. En su argumento, denomina procondicionantes a las partículas que encabezan la apódosis condicional, debido a que estos "repiten un contexto, lo resumen y lo sustituyen formalmente" (Polo 1971: 147). Aplicado al castellano medieval, asi podía actuar como un procondicionante, es decir, como proforma adverbial que actualiza la prótasis ${ }^{13}$.

13 Respecto de entonces, Montolío (1990: 127) plantea: "nos encontramos ante una pieza léxica que participa de muchas de las características funcionales de así: tiene carácter adverbial (en este caso, temporal) y funciona también como una proforma adverbial". 


\subsection{El SI COMPLETIVO}

El análisis del si completivo en los siglos XIII y XV no revela diferencias notorias respecto del uso moderno: el verbo rector es no asertivo y la interrogativa indirecta se corresponde con oraciones interrogativas de polaridad. En cuanto a la conjugación de las formas verbales que estructuran la subordinada completiva, parece haber un predominio de las fórmulas $s i$ tiene y si tendrá (16a-b).

(16a) "Desde'l cielo cató Dios sobre los fijos de Adam, por veer si ay entendedor, o requirient a Dios" (Salmo 53:5, Prealfonsina, s. XIII)

(16b) “[...] quién sabe si me apiadará el señor e que biva el niño" (2 Samuel 12:22, PA Oxford, s. XV)

Un aspecto que llama la atención de la traducción bíblica medieval tiene que ver con las partículas hebreas desde las cuales se infiere el si completivo castellano. En el hebreo hay más de una partícula capaz de activar una lectura interrogativa indirecta: está el adverbio de duda ulay, el adverbio interrogativo $h a$ y la partícula condicional $\mathrm{im}$. Por lo mismo, el proceso de traducción desde el hebreo en la Edad Media implicaba, en ciertos contextos, inferir un si completivo a partir de funciones adverbiales (Garrido Sepúlveda 2017: 387 y ss.).

\subsection{EL SI ESPECIFICADOR}

La función especificadora de si es, sin duda, la que mayores diferencias presenta respecto del uso moderno. A grandes rasgos, lo que genera el contraste entre ambos estados de lengua es la disminución, a través del tiempo, de sus funciones especificadoras, de ahí que la diacronía sea un enfoque crucial para comprender la afinidad entre los sies. Nos referiremos, pues, a tres valores del si especificador:

(a) $\mathrm{Si}$ desiderativo

(b) Si epistémico de duda

(c) $S i$ interrogativo

Respecto del matiz desiderativo y optativo, en nuestro análisis, no se evidenciaron contrastes marcados entre el uso moderno y el antiguo. Por ejemplo, tal como en el español actual, en la Edad Media la función 
desiderativa podía superponerse con la condicionalidad (17a), o bien, manifestarse en oraciones radicales (17b).

(17a) "[...] Si oviera rompido los cielos e descendido de delante ti, los montes fueran desfechos" (Isaías 63:19, E5/E7, s. XV)

(17b) “E desseó David de todo en todo agua del lago e dixo: «ịi me darié alguno a beber del agua de la cueva que es en Betlem cerca la puerta!»" (2 Samuel 23:15, General Estoria, s. XIII)

A diferencia del si desiderativo, hay un acusado contraste en la función dubitativa de $s i$ respecto del español moderno. Esta función de si equivale a la de un operador epistémico de duda como el adverbio quiça. En la base de datos estudiada, tal valor aparece con fuerza en entornos argumentativos del siglo XIII como una extrapolación del si latino (18a-b).

(18a) "Et dixo Acab a Abdías: «ve por toda la tierra do son las fuentes e las

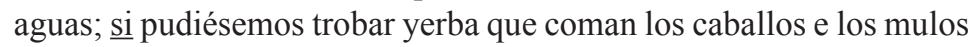
que non mueran de todo en todo»" (1 Reyes 18:5, Prealfonsina, s. XIII)

(18b) "E que 1 rogaban mucho que viniesse e que maldixiesse a aquel pueblo que les semejaba que era más fuerte que ellos. E $\underline{\text { si }} \cdot 1$ pudiessen por alguna manera vencer et echar de su tierra por el su consejo e el su fecho" (Números 22:6, General Estoria, s. XIII)

Si comparamos este tipo de registros con las traducciones paralelas del siglo $\mathrm{XV}$, notamos que los traductores se valían del adverbio quiça -traducido a partir del adverbio hebreo ulay o de la partícula im-. Es interesante, además, el hecho de que las traducciones antiguas -en concreto, la Vulgata y la Septuaginta- podían adoptar las partículas típicamente condicionales - غ̇óv y $s i-$ como equivalentes de esta función epistémica. Otra nota importante de apuntar es que el adverbio quiça, que se gramaticaliza a partir de la fórmula interrogativa qui sabe (Corominas y Pacual 1980), en el comienzo de la deriva diacrónica regía el si completivo (qui sabe si) y este conjunto tiene un significado equiparable con el de las partículas epistémicas de duda.

Si bien, como indicamos, se trata de un uso bastante atestiguado en el siglo XIII, los datos sugieren que la función epistémica de si no estaba siendo del todo diáfana para los hablantes $\mathrm{y}$, en consecuencia, comienza a perder operatividad. Como prueba de esto, está el hecho de que tal función disminuye abruptamente en el siglo XV. Además, en ciertos contextos los traductores prefieren optar por paráfrasis con interrogativas indirectas para traducir el si epistémico del latín (Garrido Sepúlveda 2017: 390-391). 
El valor que más llama la atención de las funciones especificadoras del si medieval es, sin duda, su capacidad de encabezar oraciones interrogativas radicales ${ }^{14}$. A diferencia de la función moderna, el si interrogativo medieval no se restringía a preguntas retóricas o enfáticas ${ }^{15}$, sino que habilitaba interrogaciones de polaridad (19a) y también de alternativa (19b).

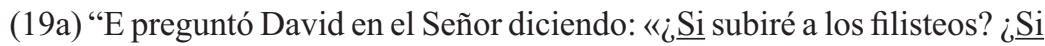
los darás en mi mano?» E dixo el Señor a David: «sube, ca dar daré a los filisteos en poder tuyo»" (2 Samuel 5:19, PA Oxford, s. XV)

(19b) “ ¿Si Dios atuerce el juizio o si el abastado atuerce las justicia?” (Job $8: 3, E 3$, s. XV)

Este hecho sugiere que había una correspondencia con los valores del $s i$ completivo, tal como la que se ejemplifica en (20a-b).

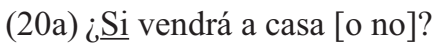

$>$ Me pregunto si vendrá a casa [o no].

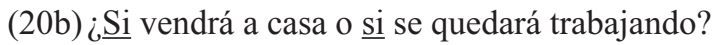

$>$ Me pregunto si vendrá a casa o si se quedará trabajando.

Enrique-Arias y Rodríguez Molina (2018) postulan que uno de los hechos cruciales que desencadenó la funcionalidad interrogativa de $s i$ fue que los traductores de la Biblia y los escritores cristianos exportaron al si latino la función completiva de la partícula griega ei, la que, a su vez, fue escogida como equivalente de las partículas interrogativas hebreas him y ha (Herman 1996: 303-306) ${ }^{16}$. Y, puesto que en el hebreo las partículas interrogativas permiten el uso independiente (no incrustado), las partículas griegas y latinas emularon esta facultad. Como último eslabón de esta cadena, está la deriva del si latino a las lenguas romances, tal como lo que hemos descrito respecto

14 Entre los pocos estudios que focalizan el si interrogativo medieval están los trabajos de Enrique-Arias y Rodríguez Molina (2018) y de Garrido Sepúlveda (2017).

15 Según Enrique-Arias y Rodríguez Molina (2018), a partir del siglo XVIII comienza a decaer la frecuencia de esta función y acaba por restringirse en exclusiva a preguntas retóricas con formas verbales en futuro y futuro perfecto de indicativo. Además, hay consenso respecto de que se trata de un valor muy infrecuente en la actualidad y casi relegado a la escritura (Escandell 1999: 3968).

16 En efecto, Brown et al. (2009: 520) han postulado que el si completivo latino es un calco del si completivo griego. Por otra parte, según Herman (1996: 303-306), otro factor que favoreció el uso interrogativo de si fue la proximidad entre contextos interrogativos y condicionales de tipo irreal. 
del si del castellano medieval. Dicha extrapolación de valores -a saber, $h a /$ him (heb.) > $\varepsilon i$ (gr.) > si (lat.) > si (esp.)- puede ejemplificarse como sigue:

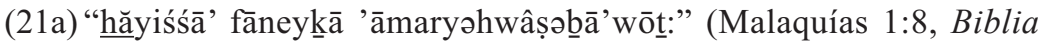
Hebrea Transliterada)

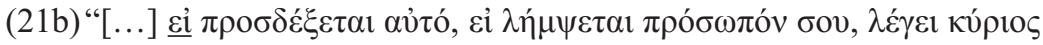
$\pi \alpha v \tau$ соко́ $\tau \omega \rho "$ (Malaquías 1:8, Septuaginta)

(21c) "[...] si placuerit ei aut $\underline{\text { si }}$ susceperit faciem tuam dicit Dominus exercituum" (Malaquías 1:8, Vulgata)

(21d) “[...] «¿ $\underline{\text { Si }}$ te querrá? ¿O si onrará tu presencia?» Dixo el Señor de las huestes" (Malaquías 1:8, Santillana, s. XV)

Además, los datos sugieren que dicha importación fue bastante efectiva, puesto que se adoptó como un recurso propio tanto en el griego, como en el latín y en el castellano medieval. Así lo evidencian varios textos del Nuevo Testamento, los cuales, por cierto, no son transliteraciones de una fuente textual hebrea (22a-c).

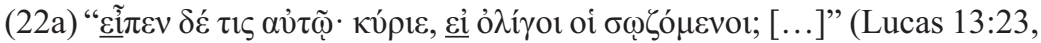
NT Tischendorf)

(22b) "ait autem illi quidam Domine si pauci sunt qui salvantur [...]" (Lucas 13:23, Vulgata)

(XI.28c) "E dixéronle algunos: «señor, ¿si son pocos aquellos que se salvan?» [...]" (Lucas 13:23, NT Lucena, s. XV)

A la luz de estos datos, Enrique-Arias y Rodríguez Molina (2018), siguiendo a Evans (2007), resumen la cadena diacrónica de si del siguiente modo:

Condicional $>$ Interrogativo indirecto $>$ Marcador $Q u$ - de polaridad ${ }^{17}$

Respecto del cambio sintáctico que va desde un contexto incrustado hacia un contexto independiente, la cadena diacrónica podría ser la siguiente (Evans 2007) $)^{18}$ :

17 Por cierto, este mismo proceso de gramaticalización de elementos Qu-, cuyo valor original es de tipo condicional, se ha documentado en otras lenguas como el yiddish (Jacobs et al. 1994: 413), el sueco (Andersson 1994, Raukko y Östman 1994), el noruego (Lie 1992: 67-68) y el alemán (Buscha 1976).

18 Curiosamente también se ha registrado la gramaticalización en el sentido inverso, esto es, desde contextos dependientes hacia contextos incrustados (Haiman 1978, Traugott 1985: 249, Heine y Kuteva 2002: 249, Ohori 2011: 643). 
Condicionalidad $>$ Subordinación $>$ Elipsis $>$ Elipsis convencionalizada $>$ Reanálisis como oración principal

En adición, hay que señalar que la situación del castellano no ha sido excepcional entre las lenguas romances; los valores interrogativos -subordinados y radicales- del si han sido reconocidos en occitano (Jensen 1990, 1994), en francés antiguo (Nyrop 1930; Marchello-Nizia 1985), en algunos dialectos sardos (Manzini y Savoia 2003) y probablemente el catalán antiguo (Enrique-Arias y Rodríguez Molina 2018).

Las ocurrencias del si interrogativo no incrustado han sido documentadas desde el Cantar de mio Cid en adelante, pero se desarrolla con mayor fuerza entre los siglos XIII y XVII. A partir del siglo XVII, la función interrogativa decae $\mathrm{y}$, como señalamos, queda marginada a preguntas retóricas. La aparición del si interrogativo no incrustado en las biblias romanceadas tiene un alto índice de registro, sin duda debido a la influencia del hebreo y del latín ${ }^{19}$, pero no siempre se trata de un calco de estas lenguas. En (23c-d), por ejemplo, las biblias romanceadas traducen $s i$ a partir de la partícula latina numquid (23b), y la Biblia del Oso (23e) hace lo mismo a partir de la partícula griega $\mu$ 门́ (23a).

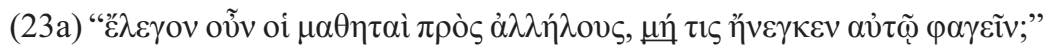
(Juan 4:33, NT Tischendorf)

(23b) "dicebant ergo discipuli ad invicem numquid aliquis adtulit ei manducare" (Juan 4:33, Vulgata)

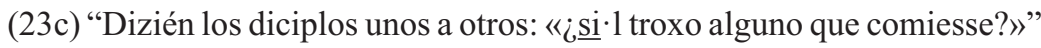
(Juan 4:33, Prealfonsina, s. XIII)

(23d) "Y dezían los deciplos a revezes «isi le dio alguno a comer?» (Juan 4:33, Misc, s. XV)

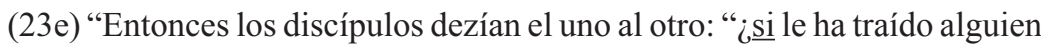
de comer?" (Juan 4:33, Biblia del Oso, s. XVI)

\subsection{El Sí AFIRMATIVO}

Según Rodríguez Molina (2014), hay algunos cambios significativos en los usos del sí afirmativo moderno respecto de su estado en la Edad Media. Una

19 De hecho, Enrique-Arias y Burguera (2010) concluyen que el si interrogativo es el mecanismo más utilizado por los traductores para transliterar las partículas interrogativas del hebreo (51\%). 
diferencia llamativa es que la función pro-oracional no se documenta en el castellano antiguo. De modo que los datos anteriores al siglo XV solo dan cuenta de contextos en que sí actúa como modificador de un SV, típicamente como fórmula de respuesta que duplica el verbo focal de la pregunta (24a-b).

(24a) "E dixo: «¿es este el vuestro hermano el menor que $m$ dixiestes?» $\mathrm{E}$

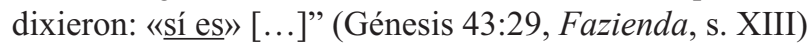

(24b) “Díxoles: «¿conocedes a Labán, fijo de Nacor?» Dixeron: «ㅅ́ conocemos" " (Génesis 29:5, Arragel, s. XV)

(24c) "E dixo: «¿si conocedes a Laván, fijo de Nahor?» E dixieron «conocemos»" (Génesis 29:5, Pentateuco E19, s. XV)

No obstante, dicha estructura podía alternar con la fórmula de respuesta latina, es decir, la repetición del verbo focal de la pregunta, sin recursos morfológicos adicionales (24c).

Otra diferencia importante reside en que la actual repartición morfológica entre sí y así no estaba claramente delimitada en el castellano antiguo, ya que el sí medieval también podía interpretarse como adverbio de manera. Por lo mismo, autoras como Batllori y Hernanz $(2008,2009)$ han argumentado que en el castellano medieval síaún no tenía el estatus de un adverbio de polaridad pleno, sino que estaba en proceso de gramaticalización. Sin embargo, los estudios que han abordado este difuso reparto entre si y así no son del todo transparentes ${ }^{20}$. En Garrido Sepúlveda (2017), hemos documentado escasos ejemplos de sí con probable valor de adverbio de modo. Consideremos los siguientes enunciados (25a-b).

(25a) "Tornaré tos judices cuemo en primero e tos consejos cuemo al compeçamiento, e pues sí serás cibdad de justicia e cibdad fiel" (Isaías 1:26, Fazienda, s. XIII)

(25b) "E tornaré los tos juezes como fueron primero e tos consejeros assí como fueron antiguamientre, des hý serás llamada ciudat de justo, villa de fiel" (Isaías 1:26, Prealfonsina, s. XIII)

En (25a), editamos como sí una partícula que no es la traducción del si latino ni del im hebreo; se trata, más bien, de una traducción de la fórmula latina post haec, que las biblias romanceadas del latín transliteran tal como se observa

20 Rodríguez Molina (2014: 870, 902), por ejemplo, describe y edita como adverbio de modo un aparente sí que la General Estoria traduce a partir de sicut, pero en realidad es un si interrogativo no incrustado y traducido del si latino ( $c f$. Garrido Sepúlveda 2017: 400). 
en (25b). Lo curioso es que la Fazienda inserta sí y, en tal contexto, parece tratarse de un adverbio de modo con el mismo valor que assí.

Otro dato significativo es que hay algunos contextos en que, a partir de la partícula condicional im del hebreo, los traductores del siglo XV intuyen la polaridad positiva $\mathrm{y}$, en consecuencia, romanzan mediante unidades adverbiales como cierto (26a) o ciertamente (26b).

(26a) "E será el que remaneciere en Cion e el que quedare en Jerusalem santo será dicho por él, todo el que fuer escripto para vidas en Jerusalem. Cierto levantará el Señor a çuzidad de dueñas de Cion e a sangres de Jerusalem enxaguará de entre ella [...]" (Isaías 4:3-4, E3, s. XV)

(26b) "E será el que quedare en Sion e fincare en Jerusalem santo le será dicho, todo escripto a vida en Jerusalem. Ciertamente lavará el Señor la haz de las fijas de Sion e los omecidios de Jerusalem desechará de en medio d'ella [...]" (Isaías 4:3-4, Santillana, s. XV)

(26c) "E será el que remaneciere en Sion e el que remaneciere en Jerusalem santo será dicho por el todo el que fuere escripto para vida en Jerusalem. Si lavará el señor la viscosidat de las fijas de Sion e las sangres de Jerusalem lavará de medio d'ella [...]" (Isaías 4:3-4, Arragel, s. XV)

En cierto modo, los traductores proceden así porque el contexto invalida una interpretación interrogativa o condicional de $\mathrm{im}$. Lo interesante es que la Biblia de Arragel opta por transliterar im mediante la partícula si (26c) y, junto a esta, ubica la forma verbal lavará, forma que anula la interpretación condicional. De modo que, una posibilidad es que la partícula $s i$ haya sido escogida por su homofonía con el sí afirmativo, como si, desde su perspectiva, fuese admisible la interpretación adverbial y afirmativa a partir de una sola unidad léxica. Como apoyo de esta idea, hay que considerar que la tilde moderna de sí es una convención muy posterior y que, de hecho, los usuarios del romance hispánico simplemente se valían de $s i$, sea para interrogativas directas o indirectas, sea para introducir condiciones o, incluso, sea para afirmar. No es de extrañar, pues, que los hablantes hubieran codificado todas estas funciones en un solo operador formal. De hecho, como veremos a continuación, la tradición gramatical y lexicográfica no siempre ha separado el $s i$ condicional del si afirmativo. 


\section{TRADICIÓN BIBLIOGRÁFICA SOBRE LA CORRESPONDENCIA DE SÍES}

Como hemos señalado, a través de la historia, las partículas sí y si han sido tradicionalmente codificadas como categorías diferenciadas. Tal vez la primera gran excepción a esta tendencia la constituye Covarrubias (1611), en cuyo diccionario introduce una sola entrada para si con el siguiente artículo: "aduerbio para afirmar, Lat. etiam parece auerse dicho de sic, algunas vezes condicional [...]". El fraseo sugiere que el autor procesaba el si condicional como un adverbio o que intuía una identidad entre los sies. Sin embargo, como lo evidencia el Nuevo tesoro lexicográfico de la lengua española (NTLLE), desde la gramática de Nebrija (1492) en adelante no hay ningún eco de esta idea.

En el siglo XIX, no obstante, surge como una nota disonante respecto de la tradición la propuesta que Andrés Bello (1847: § 415) articula en su gramática de la lengua castellana: "el sí, adverbio demostrativo de modo, el $s i$, adverbio relativo de condición, y el $s i$, adverbio interrogativo, tienen entre sí la misma afinidad, y forman la misma escala que tanto, cuanto y cuánto". Con estas palabras, Bello (1847) postula la propuesta de una correspondencia categorial entre todos los sies. Tal como se intuye en la cita, su argumento surge de la analogía posible de establecer entre los síes $\mathrm{y}$ aquellos adverbios que desempeñan una función interrogativa, relativa y focal o asertiva. Consideremos, en ese sentido, la semejanza que hay entre los ejemplos (27a-b) y (28a-b).

A. ¿Cuándo volverá?

B. Mañana volverá.

(27b) No sé cuándo volverá.

$$
\text { A. ¿Si volverá mañana? }
$$

B. Si volverá.

(28b) No sé si volverá mañana.

Es interesante notar, además, que Bello (1847) intuye una relación entre los síes y el adverbio de modo así, con el cual, desde luego, están etimológicamente emparentados. Al respecto, plantea que el si condicional rige su propio antecedente y que, en tal sentido, por tanto, equivaldría a así. Por lo pronto, una oración condicional como (29a), podría entenderse en términos de (29b). 
(29a) Te perdonaré, si te enmiendas.

(29b) Te perdonaré así, de este modo, con esta condición, si te enmiendas.

[Apud Bello 1847: § 416]

En una primera instancia, la tesis de Bello (1847) tuvo cierto eco en Hanssen (1913: §671): “en preguntas indirectas, se emplea el adverbio si"; luego, en Seco (1930: 209): “cuando en la oración interrogativa indirecta se pregunta por el predicado, la palabra de enlace es el adverbio relativo si" y, en seguida, en la gramática de la RAE (1931: § 167b). Sin embargo, no hubo intentos de profundizar en la tesis.

Recién hacia fines del siglo XX, encontramos a romanistas que reconsideraron ciertas aristas sobre la correspondencia de sies tras analizar el comportamiento de tales partículas en las lenguas romances. Por ejemplo, Christine Wimmer (1980) estudió la partícula si del francés y postuló, como hipótesis, que la conjunción condicional, el adverbio de intensificación y el adverbio de afirmación son expresiones de un único signo de lengua.

Otro caso emblemático es el estudio que Gemma Rigau (1984) publicó, respecto del catalán, con el título "De com si no és conjunció i d'altres elements interrogatius". En efecto, la autora sostiene que no es factible codificar el si interrogativo indirecto como una conjunción. Por el contrario, se trataría de una partícula $Q u$ - o adverbio con funciones relativas e interrogativas. En su argumento, Rigau (1984) arguye que el si completivo se relaciona con la polaridad de la oración subordinada y, en ese sentido, inserta una disyunción implícita, es decir, no se trataría meramente de una partícula subordinante, sino que sería un adverbio funcional en el interior de la subordinada.

Tan solo un año después, Chevalier et al. (1985) publican una investigación en la que buscan indagar en la naturaleza común entre el $s i$ condicional y el $s i / s i$ afirmativo en español y en francés. Los autores plantean que la prótasis condicional introduce una discusión crítica sobre lo procedente (o improcedente) del contenido proposicional, como si se estuviera cuestionando o evaluando el carácter veritativo de lo enunciado en la prótasis. Tal discusión se resolvería asumiendo hipotética o retóricamente el término positivo. Así, pues, una estructura condicional si $p$, $q$, se entendería en los siguientes términos: siendo cierto $p$, es cierto $q$. De este modo, salta a la vista la equivalencia del $s i$ condicional con construcciones del tipo $s i+$ $\mathrm{SV}$, equivalencia que conduce a los autores a procesar la prótasis condicional como un mecanismo retórico de afirmación o como un proyecto de frase aseverativa (cf. Chevalier et al. 1985: 147).

En cierto modo, Estrella Montolío $(1990,1999)$ también dialoga con la tesis de Bello (1847). Esta autora reflexiona sobre una posible 
correspondencia entre los sies y, al respecto, observa que el sí afirmativo, en su función de proforma oracional, es anafórico, a saber, remite a una aseveración previa, en tanto que "el si condicional es catafórico, envía a un enunciado aseverativo que le sigue" (Montolío 1990: 143). Además, en cuanto a la proximidad con el adverbio de modo así, esta lingüista afirma: "no puede perderse de vista que la partícula así puede funcionar con el valor discursivo anafórico equivalente a una prótasis condicional elíptica [...]" (Montolío 1999: 3717). Pensemos, como ejemplo, en enunciados del tipo: No he estudiado nada. Así, será mejor que no rinda el examen, donde el adverbio así equivale más o menos a una prótasis del tipo: Si no he estudiado nada.

Manzini y Savoia (2003), en un trabajo más reciente, analizaron la partícula $t f i$ de algunas variedades del sardo. Como en español, esta partícula encabeza subordinadas completivas y prótasis condicionales, pero lo interesante es que, además, actúa como elemento $Q u$ - para interrogaciones radicales tal como lo haría el adverbio cuándo. En su propuesta, ubican esta partícula dentro de un grupo al que denominan "complementantes modales" y que está al mismo nivel de operadores relativos e interrogativos (partículas $Q u-)$. De esta manera, reconocen que hay una unidad en las funciones de la partícula, que se funda en su estatus polar. En este sentido, su propuesta coincide parcialmente con la tesis de Andrés Bello.

En una línea similar, Lluïsa Hernanz (2012: 158) postula que "las lecturas condicional e interrogativa no serían sino dos posibles manifestaciones de un valor básico de carácter más general que vamos a suponer va ligado a la expresión de la irrealidad”. De hecho, la irrealidad propia del contexto condicional, como ya señalamos, es entendida en términos de una negación implícita. La noción de que la partícula si se engarza con la polaridad también ha sido observada por autores como Adger y Quer (2001) y Brucart y Gallego (2009). En palabras de estos últimos, "el que tenen en comú les interrogatives indirectes totals i les pròtasis condicionals és el fet que el valor de veritat de l'enunciat resta suspès" (Brucart y Gallego 2009: 182). No obstante, respecto de la tesis de Bello (1847), los autores precisan: "una aplicació literal de la proposta del gramàtic veneçolà resulta difícil de defensar empíricament" (Brucart y Gallego 2009: 177).

Este sucinto panorama bibliográfico permite visibilizar a un conjunto importante de autores que han reflexionado sobre la aparente correspondencia de sies. Si bien la aproximación de cada cual presenta diferencias en cuanto al grado y tipo de identidad que postulan para los sies, lo cierto es que podemos trazar, a través de ellos, una tradición de reflexión gramatical que ha reproducido, directa o indirectamente, el eco de la controvertida tesis de Bello (1841). 


\section{SÍNTESIS DE ARGUMENTOS}

En los apartados previos, hemos elaborado un registro de aquellos hechos a partir de los cuales se perfila cierta proximidad gramatical entre todos los sies, a saber, el origen de tales partículas y sus valores en el castellano medieval y moderno. Asimismo, compendiamos los aportes bibliográficos que en cierto grado podrían alinearse con la propuesta de Bello (1847). A continuación, pues, proporcionamos una síntesis de los principales argumentos aducidos en favor de la correspondencia semántica y/o categorial entre los sies.

\subsection{ProcedenCIA Y DERIVA DIACRÓNICA}

Tras revisar el origen de las partículas $s i$, si y así, hemos aludido a que todas se remontan a una misma proforma adverbial del indoeuropeo. Esta proforma habría comenzado a especializarse y su derivación produjo las partículas SĪ y SİC. En esta fase, SİC operaba como adverbio de modo y SĪ es descrita como una conjunción que, en general, codifica valores completivos y condicionales. No obstante, hay casos en que la conjunción mantenía la función catafórica propia de su pasado adverbial (Ernout y Thomas 1989: 374). En este sentido, es válido intuir que su cadena de gramaticalización (adverbio > conjunción) aún no estaba completa.

La derivación de SĪC aportó los adverbios neolatinos sí y así, en tano que SĪ pasó al romance con la misma funcionalidad original. El análisis de $s i$ en los textos medievales sugiere que, en ciertos contextos, seguía siendo recuperable su función de proforma adverbial. Algunos indicadores de este hecho son la afinidad semántica entre el si condicional y el adverbio de modo así, la similitud del $s i$ especificador con adverbios epistémicos o interrogativos, y el aparente procesamiento que los hablantes hacían de $s i$ y sí como una sola pieza léxica ( $c f$. Covarrubias 1611).

\subsection{Analogía CON OtRos ADVERBios}

El argumento básico de la propuesta de Andrés Bello (1847) se dirige a la analogía que puede ser establecida entre la distribución sintáctica de los sies y la de adverbios que desempeñan funciones interrogativas (cuándo), relativas (cuando) y asertivas (entonces). Así pues, tenemos un si interrogativo obsolescente (30a), un si relativo -sea el condicional o el interrogativo indirecto- (30b-c) y un sí asertivo (30d). 


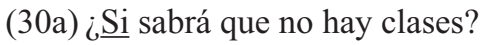

(30b) $\underline{\mathrm{Si}}$ sabe que no hay clases, se quedará en su casa.

(30c) No sé si sabe.

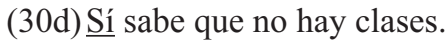

Una de las críticas más explícitas a este argumento fue formulada por Lidia Contreras (1957), quien manifestó lo siguiente:

Nosotros estamos de acuerdo con los que estiman que [...] el si funciona como conjunción. Si se le ha considerado adverbio es, seguramente, porque la estructura de las oraciones en que él aparece es similar, formalmente, a la de otras interrogativas indirectas, como puede verse: No sé cómo llegó, Debería decirme cuánto le debo, Quisiera saber cuándo vendrá, Mira dónde está, etc. Y en estos casos las expresiones cómo, cuánto, cuándo, dónde, etc., son evidentemente adverbios, pues determinan la significación del elemento verbal de la suboración a que pertenecen, indicando respectivamente modo, cantidad, tiempo, lugar. Pero en ejemplos como: Quiero saber si está en casa, el si no ostenta valores sintácticos ni semánticos similares; es meramente un elemento de relación, revelador, con otros elementos, del carácter interrogativo de la oración. (Contreras 1957: 72-73)

Como se aprecia en la cita, Contreras (1957) reconoce la analogía entre el si y los adverbios interrogativos, pero argumenta que aquel no desempeña una función gramatical como adjunto del verbo de la subordinada $\mathrm{y}$, en consecuencia, no puede procesarse como adverbio. Sin embargo, en el interior de la subordinada sí que es factible procesar el si complementante como aquel que, además de subordinar, pone en suspensión la polaridad tal como lo haría en interrogativas directas, de ahí que sea expletivo el enunciado (31a) y agramatical -o, al menos, no aceptable- el caso de (31b).

(31a) Me gustaría saber si tú no estabas ayer.

(32b)* Me gustaría saber si tú sí estabas ayer.

\subsection{ESTATUS POLAR}

El estatus polar es, sin lugar a dudas, el más claro punto de contacto entre todos los síes: en oraciones asertivas que seleccionan el adverbio $s i$, la polaridad es afirmativa y enfática; en oraciones condicionales no irreales, $s i$ encabeza prótasis con polaridad suspendida, en tanto que, en oraciones condicionales irreales, la polaridad está implícitamente negada; 
en subordinadas interrogativas indirectas, la partícula si incrusta segmentos de carácter incierto y la construcción es gramatical solo si la partícula está regida por un verbo no asertivo; en interrogativas directas, si suspende la polaridad del enunciado y, típicamente en preguntas retóricas, implica la polaridad de la respuesta; como especificador, $s i$ ha codificado valores que ponen en suspensión la polaridad (tal como el adverbio quizás), o bien, que presentan el contenido proposicional como implícitamente negado (tal como ojalá + imperfecto de subjuntivo). Esta gama de matices puede observarse con mayor nitidez en la siguiente tabla.

\begin{tabular}{|l|c|c|c|c|}
\hline \multirow{2}{*}{ función } & \multicolumn{3}{|c|}{ polaridad } \\
\cline { 2 - 5 } & afirmativa & suspendida & $\begin{array}{c}\text { implícitamente } \\
\text { negada }\end{array}$ & $\begin{array}{c}\text { implicada } \\
\text { (afirmativa o } \\
\text { negativa) }\end{array}$ \\
\hline si afirmativo & $\mathrm{X}$ & & & \\
\hline $\begin{array}{l}\text { si condicional (no } \\
\text { irreal) }\end{array}$ & & $\mathrm{X}$ & & \\
\hline si condicional (irreal) & & & $\mathrm{X}$ & \\
\hline $\begin{array}{l}\text { si interrog a tivo } \\
\text { indirecto }\end{array}$ & & $\mathrm{X}$ & & \\
\hline si interrogativo directo & & $\mathrm{X}$ & & $\mathrm{X}$ \\
\hline si epistémico de duda & & $\mathrm{X}$ & & \\
\hline si desiderativo & & $\mathrm{X}$ & $\mathrm{X}$ & \\
\hline
\end{tabular}

Tabla I. La polaridad de los síes (cf. Garrido Sepúlveda 2017: 405)

\subsection{Otras Lenguas}

Ha sido interesante constatar que la correspondencia entre los síes parece ser más que una coincidencia formal, producto de la diacronía. Las investigaciones en otras lenguas han llevado a reconocer, en ciertas partículas, la existencia de una migración de valores que van desde la condicionalidad hacia la interrogación directa e indirecta. Dichas partículas son conocidas, en la sintaxis formal, como elementos $Q u$-, a saber, aquellos adverbios que operan como relativos, interrogativos y exclamativos. Esta conexión se ha respaldado con datos provenientes de algunas lenguas romance, como el sardo, el occitano y el francés medieval, y en otras lenguas como el alemán, el noruego y el yiddish. 
En relación con esta cadena de gramaticalización, los datos provenientes de la traducción bíblica medieval son de una importancia crucial, puesto que en este tipo de textos está la evidencia del trasvase de valores que va desde el hebreo del Tanaj hacia el griego de la Septuaginta, luego llega al latín de la Vulgata y, desde ahí, se difunde a lenguas neolatinas como el romance castellano.

\section{CONCLUSIONES}

A tenor de todo lo expuesto, estimamos que hay al menos un par de tesis que permiten integrar de modo coherente los datos que hemos aportado. En primer lugar, es posible formular una tesis moderada y reconocer tan solo una correspondencia semántica -y no categorial-basada en el estatus polar de todos los síes. No obstante, incluimos en esta tesis la idea de que, durante la Edad Media, persistieron los usos de $s i$ como proforma adverbial y, en ese sentido, todavía no se había completado su reanálisis como conjunción. A partir del siglo XVI, la producción de diccionarios y gramáticas, la convención ortográfica entre sí y si, la decadencia del si interrogativo directo, y la analogía con diccionarios y gramáticas latinas condujeron a que, a la postre, $s i$ se codificara como una conjunción y se disociara definitivamente del adverbio sí. Esta tesis moderada se ajusta mucho mejor con la idea de que el cambio lingüístico es gradual y, por lo mismo, no es posible establecer límites categoriales tan rígidos a aquellas estructuras que están en vías de gramaticalización.

En segundo lugar, reconocemos una tesis fuerte -como la de Andrés Bello-, desde la cual podría postularse tanto una correspondencia semántica como categorial entre todos los síes. Dicho de otro modo, desde esta perspectiva, las antiguas y presentes manifestaciones adverbiales de si no son meros ecos de su etimología o deriva diacrónica, sino que son pruebas en favor de su actual estatus adverbial.

Desde nuestra perspectiva, no obstante, la tesis fuerte depende demasiado de una concepción monolítica del cambio lingüístico. Por lo mismo, sobre la base de que el proceso de gramaticalización no puede producir instantáneamente conjunciones a partir de adverbios, la tesis moderada nos parece una propuesta que se ajusta mejor con aquel continuum que es el cambio lingüístico. 


\section{REFERENCIAS BIBLIOGRÁFICAS}

Adger, David y Josep Quer. 2001. The Syntax and Semantics of Unselected Embedded Questions. Language 77: 107-133.

Alarcos, Emilio. 1994. Gramática de la lengua española. Madrid: Espasa Calpe.

Andersson, Erik. 1994. Swedish. En Ekkehard Köning and Johan van der Auwera (eds.). The Germanic Languages, pp. 271-312. London: Routledge.

Batllori, MontSerrat y M. Llü̈sa Hernanz. 2008. La polaridad negativa enfática en español: Un estudio diacrónico y comparativo. En C. Company y J. Moreno de Alba (eds.). Actas del VII Congreso Internacional de Historia de la Lengua Española. Tomo 2, pp. 11831200. Madrid: Arco/Libros.

2009: En torno a la polaridad enfática en español y en catalán: un estudio diacrónico y comparativo. En Joan Rafel (ed.). Diachronic Linguistics, pp. 373-406. Girona: Documenta Universitaria.

Bello, AndRÉs. 1916 [1847]. Gramática de la lengua castellana destinada al uso de los americanos. Francia: R. Roger y F. Chernoviz Editores.

Brown, H. Paul, Brian D. Joseph y Rex E. Wallace. 2009. Questions and answers. En Philip Baldi y Pierluigi Cuzzolin (eds.). New Perspectives on Historical Latin Syntax 1. Syntax of the Sentence, pp. 489-530. Berlin / New York: Mouton de Gruyter.

Brucart, Joser M. y Ángel Gallego. 2009. L'estudi formal de la subordinació i l'estatus de les subordinades adverbials. Llengua i literatura: Revista anual de la Societat Catalana de Llengua i literatura 20: 139-191.

Buscha, AnNerose. 1976. Isolierte Nebensätze im dialogischen Text. Deutsch als Fremdsprache 13: $274-279$.

Chevalier, Jean Claude, Michel Launay y Maurice Molho. 1985. Del morfema si (Hipótesis y afirmación en español y en francés). Philologica Hispaniensia in Honorem Manuel Alvar, vol. II, pp. 129-166. Madrid: Gredos.

CONTRERAs, Lidia. 1957. Oraciones interrogativas con si. Boletín de Filología de la Universidad de Chile 9: 67-86.

Corominas, Joan y José A. Pascual. 1980. Diccionario crítico etimológico castellano e hispánico. Madrid: Gredos.

Covarrubias. Sebastián DE. 1611. Tesoro de la lengua castellana o española. Madrid.

ENRIQUe-AriAs, ANDRÉs (dir.). 2008. Biblia medieval. Universitat de les Illes Balears. En línea en $<$ http://www.bibliamedieval.es $>$.

EnRIQUe-Arias, ANDrés y JoAn BuRguera. 2010. Variación y cambio en la formalización de la interrogación retórica en la historia del español. XXVI Congreso Internacional de Lingüística y Filología Románicas (Universidad de Valencia, 6-11 de septiembre de 2010), Valencia.

EnriQue-Arias, Andrés y Javier Rodríguez Molina. 2018. Si as a Q particle in Old Spanish. En Miriam Bouzouita y Enrique Pato (eds.). Studies in Historical Ibero-Romance MorphoSyntax, pp. 249-274. Amsterdam/Philadelphia: John Benjamins.

Ernout, Alfred y Antoine Meillet. 1959. Dictionnaire étymologique de la langue latine: Histoire de mots. París: Editorial Libraire Klincksieck.

Ernout, Alfred y François Thomas. 1989. Syntaxe Latine. París: Editorial Libraire Klincksieck.

Escandell, M ${ }^{\text {a }}$ Victoria. 1999. Los enunciados interrogativos. Aspectos semánticos y pragmáticos. En Ignacio Bosque y Violeta Demonte (dirs.). Gramática descriptiva de la lengua española, pp. 3929-3991. Madrid: Espasa-Calpe. 
Evans, Nicholas. 2007. Insubordination and its uses. En Irina Nikolaeva (ed.). Finiteness: Theoretical and Empirical Foundations, pp. 366-431. Oxford: OUP.

Garrido Sepúlveda, Claudio. 2015. La restructuración de las oraciones condicionales desde el latín al español medieval: hacia un estado de la cuestión. Onomázein 31: 187-204.

2017. La expresión de la condicionalidad en los romanceamientos bíblicos medievales. Tesis doctoral, Barcelona: Universidad Autónoma de Barcelona.

González Rodríguez, Raquel. 2007. Sintaxis y semántica de la partícula de polaridad sí. Revista Española de Lingüística 37: 311-336.

Haiman, John. 1978. Conditionals Are Topics. Lan 54: 564-589.

Hanssen, Federico. 1913. Gramática histórica de la lengua castellana. Halle: Max Niemeyer.

Heine, Bernd y Tania Kuteva. 2002. World lexicon of grammaticalization. Cambridge: Cambridge University Press.

Herman, JózSEF. 1996. A propos du si interrogatif: évolutions achevées et évolutions bloquées. En Alfred Bammesberger \& Friedrich Heberlein (eds.). Akten des VIII. Internationalen Kolloquiums zur lateinischen Linguistik, pp. 296-307. Heidelberg: Winter.

HernanZ, M. Lluïsa. 2012. Sobre la periferia izquierda y el movimiento: el complementante "si”" en español. En J. M. Brucart y A. Gallego (coords.). El movimiento de constituyentes, pp. 151-171. Madrid: Visor.

Jacobs, Neil G., Ellen F. Prince y Johan van der Auwera. 1994. Yiddish. En Ekkehard Köning and Johan van der Auwera (eds.). The Germanic Languages, pp. 388-419. London: Routledge.

Jensen, Frede. 1990. Old French and Comparative Gallo-Romance Syntax. Tübingen: Max Niemeyer Verlag.

1994. Syntaxe de l'ancien Occitan. Tübingen: Max Niemeyer Verlag.

LAKA, ITZIAR. 1990. Negation in syntax: On the nature of functional categories and projections. Tesis doctoral. Cambridge: The MIT Press.

Lewis, Charlton y Thomas Short. 1879. A new Latin Dictionary, Oxford: Clarendon Press. LIE, Svein. 1992. Ka du sei?. Maal og Minne 1992: 62-77.

Manzini, M. Rita y Leonardo Savoia. 2003. The Nature of Complementizers. Rivista di Grammatica Generativa 28: 87-110.

Marchello-Nizia, Christiane. 1985. Dire le vrai: l'adverbe "si" en français médiéval. Essai de linguistique historique. Genevè: Librairie Droz.

Monteil, Pierre. 1973. Eléments de phonétique et de morphologie du latin. París: Nathan.

Montolío, Estrella. 1990. Expresión de la condicionalidad en español. Tesis Doctoral. Barcelona: Universidad de Barcelona.

1999. Las construcciones condicionales. En Ignacio Bosque y Violeta Demonte (dirs.). Gramática descriptiva de la lengua española, pp. 3643-3737. Madrid: EspasaCalpe.

Nebrija, Antonio De. 1980 [1492]. Gramática de la lengua castellana. Madrid: Editora Nacional.

Nicholson, George. 1938. Romance si (se) from Latin sit. Hispanic Review 6: 250-257.

Nyrop, Kristoffer. 1930. Grammaire historique de la langue française. Copenhage: Gyldendalske Boghandel.

OHoRi, Toshiо. 2011. The grammaticalization of subordination. En Heiko Narrog \& Bernd Heine (eds.). The Oxford Handbook of Grammaticalization, pp. 636-645. Oxford: OUP.

Polo, José. 1971. Las oraciones condicionales en español (ensayo de teoría gramatical). Granada: Universidad de Granada.

RaUkKo, JaRNo AND JAN-Ola Östman. 1994. Pragmaattinen näkökulma itämeren kielialueeseen. Helsinki: University of Helsinki, Department of General Linguistics, Publications. 
Real Academia Española. 1931. Gramática de la lengua española. Madrid: Espasa Calpe. 2009. Nueva Gramática de la lengua española. Madrid: Espasa Libros.

Rigau, Gemma. 1984. De com si no és conjunció i d'altres elements interrogatius. Estudis Gramaticals / Working Papers in Linguistics 1: 249-278.

RodrígueZ Molina, Javier. 2014. La gramática oculta de la polaridad positiva en español antiguo. RILCE: Revista de Filología Hispánica 30 (3): 861-915.

SANJuÁn, Felisa. 1999. Partícula condicional si. Español actual: Revista de español vivo 72: 41-46.

Seco, Rafael. 1971 [1930]. Manual de gramática española. Madrid: Aguilar.

Traugott, Elizabeth. 1985. Conditional markers. En John Haiman (ed.). Iconicity in Syntax, pp. 289-307. Amsterdam: John Benjamins.

VAsco DA GAMA, NiLton. 1979. La polysémie et la polyfonctionnalité du français si. Essai d'explication inter-romance. Tralili 17: 27-85.

Veiga, AleXandre. 1991. Condicionales, concesivas y modo verbal en español. Santiago de Compostela: Anexo 34 de Verba. Anuario Galego de Filoloxía.

1999. La tipología de las oraciones condicionales castellanas en publicaciones recientes: el peso de una tradición en la investigación lingüística. En Actas del I Congreso Internacional de Historiografia Lingüistica Española, pp. 685-698. Barcelona: Arco/ Libros.

Wimmer, Christine. 1980. Les si conjonctions et la lexigenèse de si. Neuphilologische Mitteilungen 83 (3): 313-328. 